\title{
Responsive aqueous foams stabilised by silica nanoparticles hydrophobised in situ with a conventional surfactant
}

Yue Zhu, ${ }^{\mathrm{a}}$ Xiaomei Pei, ${ }^{\mathrm{a}}$ Jiangzhong Jiang, ${ }^{\mathrm{a}}$ Zhenggang Cui ${ }^{\mathrm{a}}$ and Bernard P. Binks ${ }^{\mathrm{b}}$ *

${ }^{\mathrm{a}}$ The Key Laboratory of Food Colloids and Biotechnology, Ministry of Education, School of Chemical and Material Engineering, Jiangnan University, 1800 Lihu Road, Wuxi, Jiangsu 214122, P.R. China

${ }^{\mathrm{b}}$ Department of Chemistry, University of Hull, Hull. HU6 7RX. UK *Corresponding authors: cuizhenggang@hotmail.com; b.p.binks@hull.ac.uk

Supporting information

Table of Contents

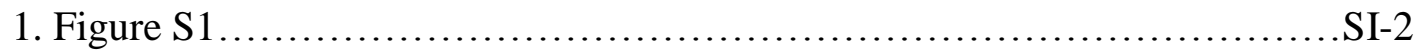

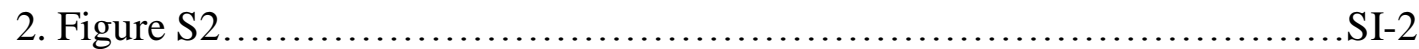

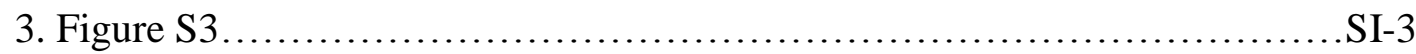

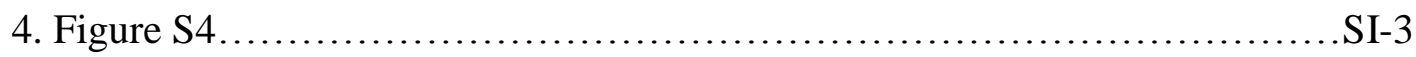

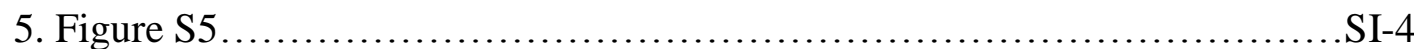

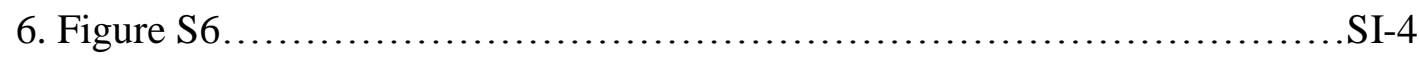

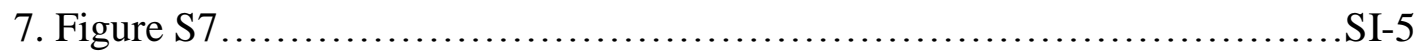

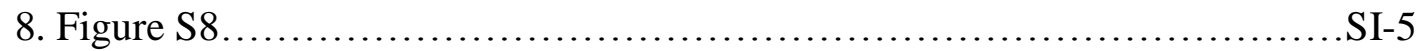



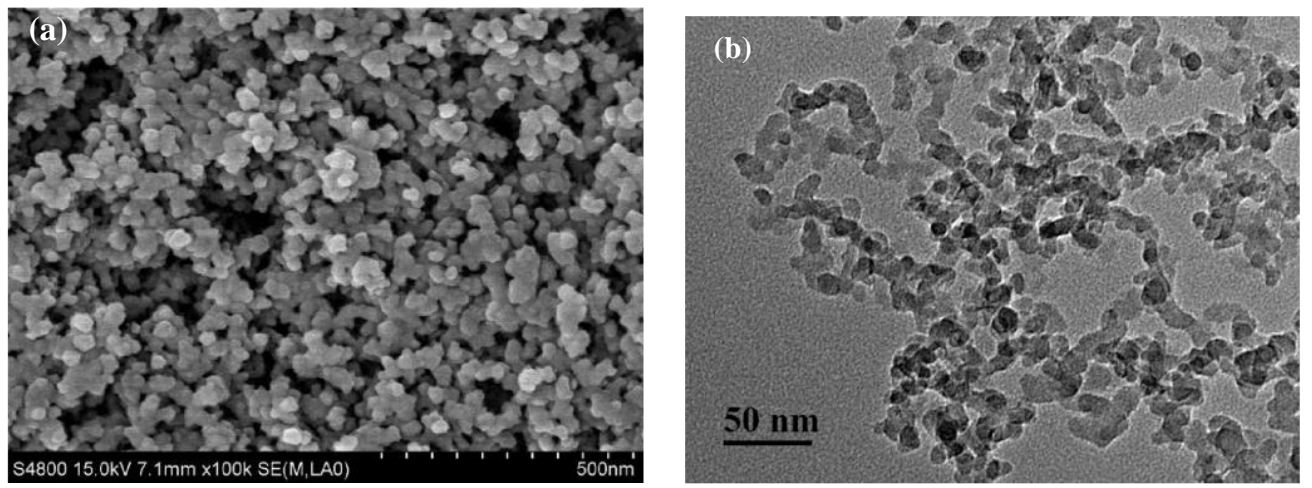

Figure S1. (a) SEM image and (b) TEM image of powdered silica nanoparticles of HL-200 with a BET surface area of $200 \pm 20 \mathrm{~m}^{2} \mathrm{~g}^{-1}$.

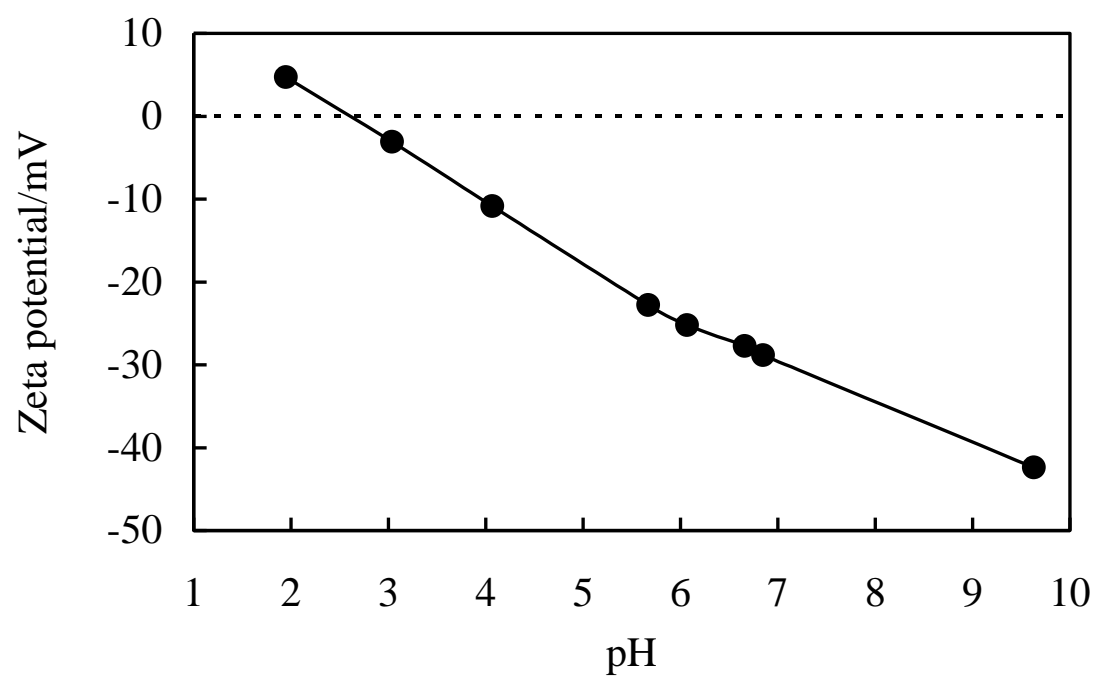

Figure S2. Zeta potentials of $0.1 \mathrm{wt} . \%$ silica nanoparticles dispersed in water of different $\mathrm{pH}$, measured $24 \mathrm{hr}$. after dispersion at $25^{\circ} \mathrm{C}$. 


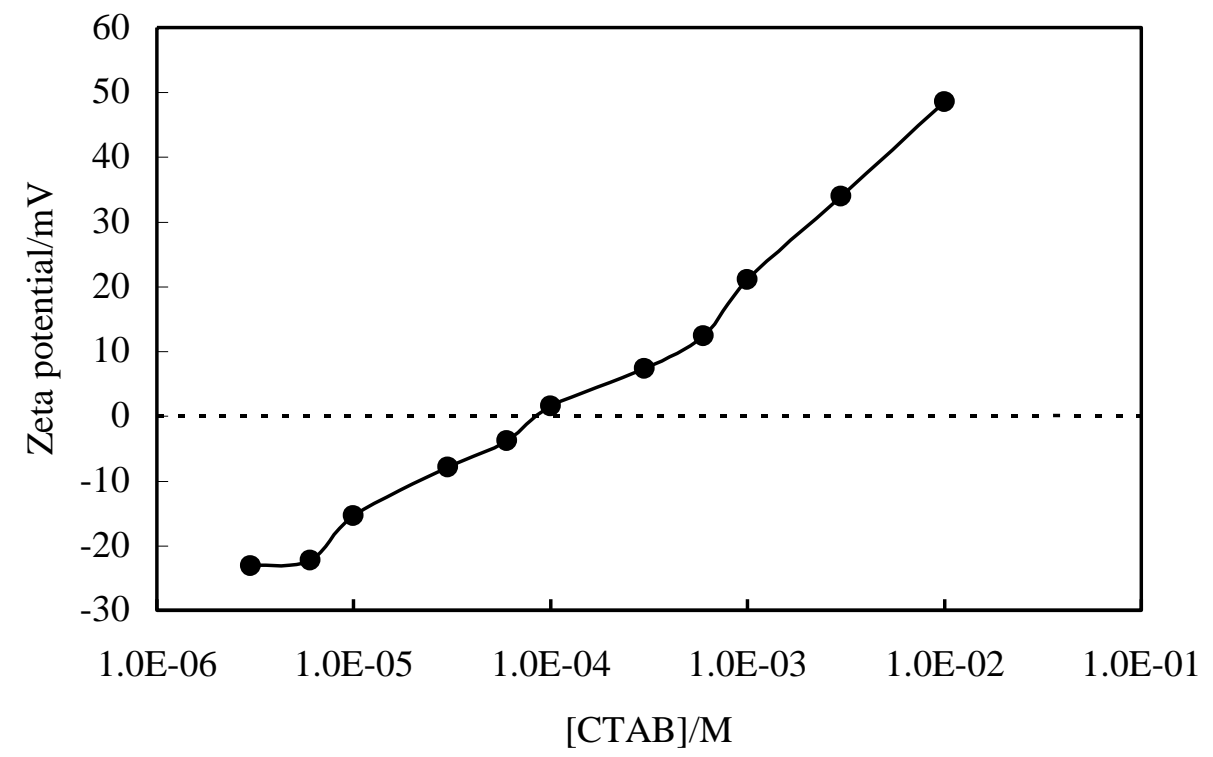

Figure S3. Zeta potential of $0.1 \mathrm{wt} . \%$ silica nanoparticles dispersed in aqueous CTAB solutions as a function of surfactant concentration at $25^{\circ} \mathrm{C}$.

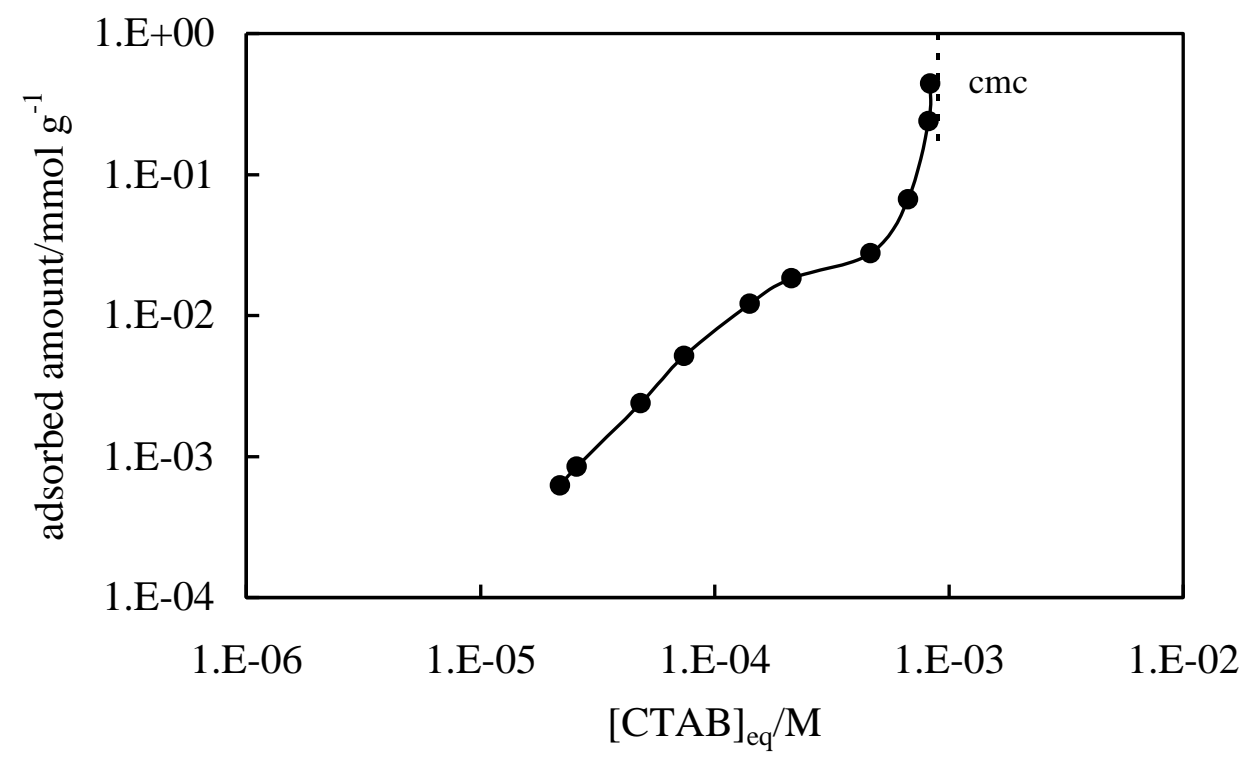

Figure S4. Adsorption isotherm of CTAB at the silica nanoparticle-water interface at $25^{\circ} \mathrm{C}$. 

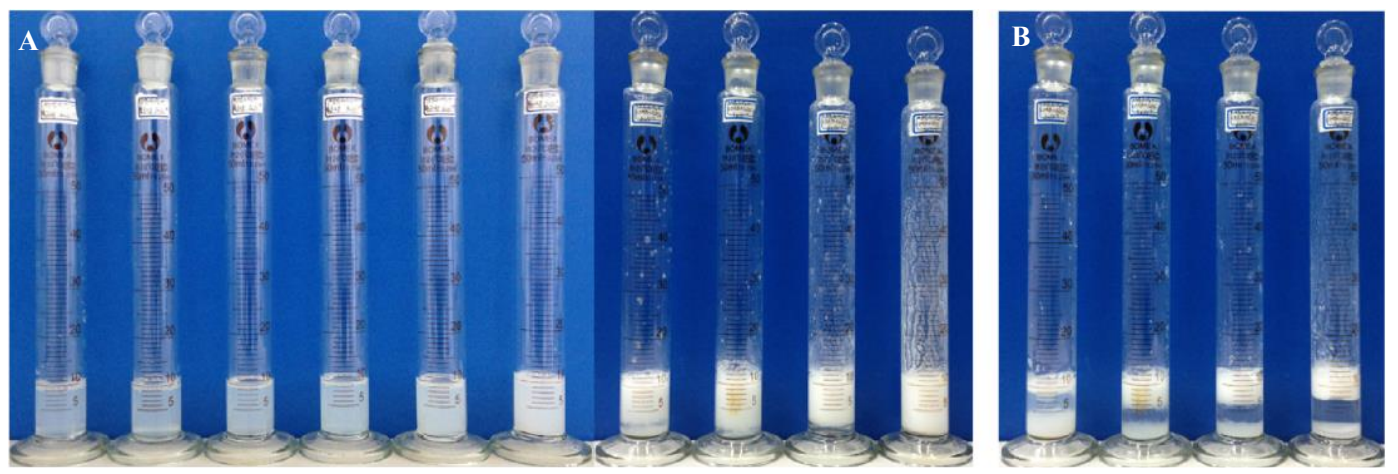

Figure S5. Photos of vessels containing $10 \mathrm{~cm}^{3}$ of a dispersion of $0.5 \mathrm{wt} . \%$ silica nanoparticles in an equimolar mixture of aqueous CTAB and SDS at different individual concentrations immediately (A) and $1 \mathrm{hr}(\mathrm{B})$ after shaking. CTAB or SDS concentration (from left to right): 0.06, 0.1, 0.2, 0.3, 0.6, 1, 2, 3, 6 and $10 \mathrm{mM}(\mathrm{A}) ; 2$, 3, 6 and $10 \mathrm{mM}$ (B). No foam was produced at concentrations $\leq 1 \mathrm{mM}$.
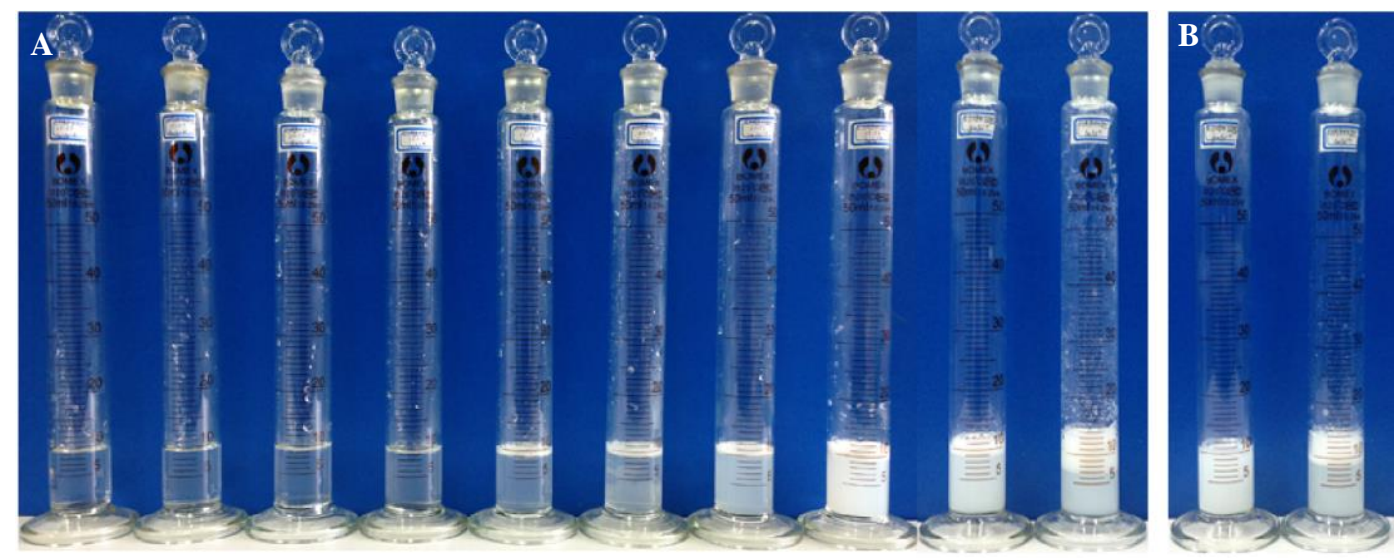

Figure S6. Photos of vessels containing $10 \mathrm{~cm}^{3}$ aqueous solution of an equimolar mixture of CTAB and SDS at different individual concentrations taken immediately (A) and $24 \mathrm{hr}$ after shaking (B). CTAB or SDS concentration (from left to right): 0.01, 0.03, 0.06, 0.1, 0.3, 0.6, 1, 3, 6 and $10 \mathrm{mM}(\mathrm{A}) ; 6$ and $10 \mathrm{mM}(\mathrm{B})$. No foam was produced at concentrations $\leq 3 \mathrm{mM}$. 


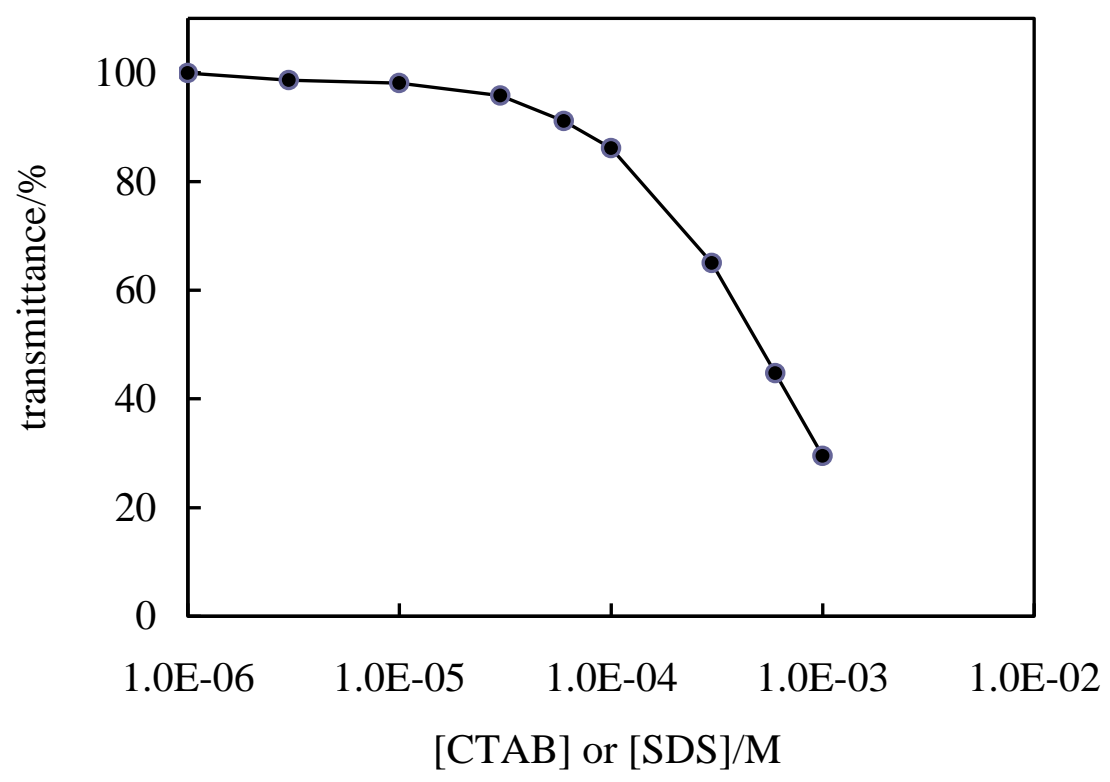

Figure S7. Transmittance of aqueous solutions of an equimolar mixture of CTAB and SDS at $25{ }^{\circ} \mathrm{C}$ measured at $600 \mathrm{~nm}$, with pure water as reference.
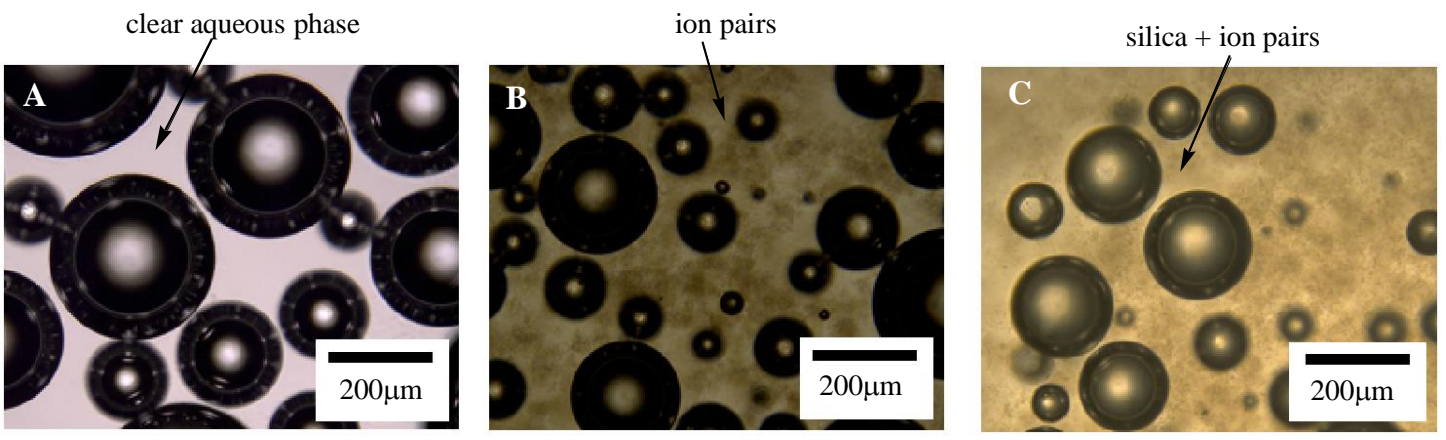

Figure S8. Micrograph of foams stabilized by 0.5 wt.\% silica nanoparticles + CTAB at $0.2 \mathrm{mM}(\mathrm{A}), \mathrm{CTAB} / \mathrm{SDS}$ mixture at $10 \mathrm{mM}(\mathrm{B})$ and $0.5 \mathrm{wt} . \%$ silica nanoparticles + CTAB/SDS mixture at $10 \mathrm{mM}$, respectively. 